University of Rhode Island

DigitalCommons@URI

Civil \& Environmental Engineering Faculty

Publications

Civil \& Environmental Engineering

2019

\title{
Microstructure-guided numerical simulation to evaluate the influence of phase change materials (PCMs) on the freeze-thaw response of concrete pavements
}

\author{
Sumeru Nayak \\ University of Rhode Island \\ N.M. Anoop Krishnan \\ Sumanta Das \\ University of Rhode Island, sumanta_das@uri.edu
}

Follow this and additional works at: https://digitalcommons.uri.edu/cve_facpubs

The University of Rhode Island Faculty have made this article openly available.

Please let us know how Open Access to this research benefits you.

This is a pre-publication author manuscript of the final, published article.

Terms of Use

This article is made available under the terms and conditions applicable towards Open Access

Policy Articles, as set forth in our Terms of Use.

\section{Citation/Publisher Attribution}

Nayak, S., Krishnan, N.M. A., \& Das, S. (2019). Microstructure-guided numerical simulation to evaluate the influence of phase change materials (PCMs) on the freeze-thaw response of concrete pavements.

Construction and Building Materials, 201, 246-256. doi: 10.1016/j.conbuildmat.2018.12.199

Available at: https://doi.org/10.1016/j.conbuildmat.2018.12.199

This Article is brought to you for free and open access by the Civil \& Environmental Engineering at DigitalCommons@URI. It has been accepted for inclusion in Civil \& Environmental Engineering Faculty Publications by an authorized administrator of DigitalCommons@URI. For more information, please contact digitalcommonsgroup@uri.edu. 


\title{
Microstructure-guided Numerical Simulation to Evaluate the Influence of Phase Change Materials (PCMs) on the Freeze-thaw response of Concrete Pavements
}

\author{
Sumeru Nayak ${ }^{1}$, N. M. Anoop Krishnan ${ }^{2}$, Sumanta Das ${ }^{3 *}$ \\ ${ }^{1}$ Graduate Student, Civil and Environmental Engineering, University of Rhode Island, Kingston, \\ RI 02881, United States \\ ${ }^{2}$ Assistant Professor, Department of Civil Engineering, Indian Institute of Technology Delhi, \\ Hauz Khas, New Delhi-110016, India \\ 3*Assistant Professor, Civil and Environmental Engineering, University of Rhode Island, \\ Kingston, RI 02881, United States, Email: sumanta_das@uri.edu (corresponding author)
}

\begin{abstract}
The use of phase change materials in infrastructure has gained significant attention in the recent years owing to their robust thermal performance. This study implements a numerical simulation framework using finite element analysis to evaluate the influence of Phase Change Materials (PCMs) on the thermal response of concrete pavements in geographical regions with significant winter weather conditions. The analysis is carried out at different length scales. The latent-heat associated with different PCMs is efficiently incorporated into the simulation framework. Besides, the numerical simulation framework employs continuum damage mechanics to evaluate the influence of PCMs on the freeze-thaw induced damage in concretes. The simulations show significant reductions in the freeze-thaw induced damage when PCMs are incorporated in concrete. The numerical simulation framework, developed here, provides efficient means of optimizing the material design of such durable PCM-incorporated concretes for pavements by tailoring the composition and material microstructure to maximize performance.
\end{abstract}

Keywords: Microstructure; Finite element; Numerical homogenization; Damage; Freeze-thaw; Phase Change Materials (PCMs). 


\section{INTRODUCTION}

Use of Phase change materials (PCMs) in cementitious composites for enhanced energy efficiency is an active research area [1-4]. PCMs have been shown to be advantageous in structural concretes due to their ability to store and release heat $[2,4-6]$. A large number of studies have focused on the use of PCMs towards indoor thermal comfort in buildings and enhancement of building energy efficiency [6-9]. Besides, PCMs have been shown to reduce early age hydration heat release and the early-age thermal cracking in large concrete structures and pavements [10-12]. In addition to the above-mentioned applications, availability of these PCMs with a wide range of transition temperatures [1,13] opens up various innovative avenues towards beneficial utilization of these materials in infrastructure materials. For example, application of PCMs towards reduction in freeze-thaw cycles in concretes pavements has been proposed earlier [4,13]. Deicing salts are commonly used to remove snow and ice from the pavement surfaces [4,13-17]. But, such process is labor-intensive and causes damage to the pavements $[4,13,18,19]$. Alternatively, incorporation of PCMs in concretes has been suggested $[1,4,20]$ to solve this issue by the means of high latent heat of fusion of PCMs. A recent experimental study [4] has shown significant reduction in snow formation when PCMs are incorporated in concrete. Another recent study confirmed improved frost resistance of the concrete containing PCMs [20]. Numerical studies involving freeze-thaw performance of cementitious materials are also implemented using one dimensional finite difference technique $[10,13,20]$.

This paper focuses on microstructure-guided numerical simulation using finite element analysis to evaluate the influence of microencapsulated paraffinic PCMs with transition temperature around $5^{\circ} \mathrm{C}$ on the freezethaw response of macro-scale concrete pavements. The numerical simulation framework, presented in this study, performs numerical homogenization using finite element analysis at multiple length scales. The effective properties, obtained using multi-scale numerical homogenization, are employed in a macro-scale FE model of concrete pavement to obtain pavement temperatures under the effects of the ambient temperature and solar radiation whilst considering conduction, convection and radiation modes of heat transfer with the subgrade and the atmosphere. The pavement temperatures, thus obtained, are used to quantify frost damage at multiple length scales using continuum damage mechanics [21-24] that can capture the progressive freeze-thaw induced damage. Thus, this study integrates the material microstructure and thermo-mechanical properties of the constituent phases to predict the freeze-thaw response of macroscale concrete pavement. The numerical simulation framework, presented in this study, provides efficient design strategies to tailor the composition and microstructure towards development of concretes with improved frost-damage performance without compromising its strength. Hence, the methodology developed herein would be extremely useful for pavements in areas with severe winter weather conditions. 


\section{NUMERICAL SIMULATION TO ELUCIDATE THE INFLUENCE OF PCM ON THERMAL RESPONSE OF CONCRETE PAVEMENTS}

In this paper, a thermal analysis is carried out at multiple length scales with a view to evaluate the influence of PCMs in concrete pavements. Here two different material mixtures are considered. While the control concrete contains $70 \%$ aggregates (40\% coarse aggregate and $30 \%$ fine aggregate) by volume, the PCMincorporated concrete contains $64 \%$ aggregates (40\% coarse aggregate and $24 \%$ fine aggregate) and $6 \%$ microencapsulated paraffinic PCMs (as 20\% volumetric sand-replacement) by volume. Such dosage of PCM has been shown to provide equivalent mechanical performance as compared to conventional mortars [25]. In this study the dosage of PCMs is fixed at $20 \%$ by volume sand substitute since incorporation of higher volume fraction of PCMs has been shown to result in decrease in compressive and flexural strength in a previous study [25]. PCM considered here has phase transition temperature of $5.1^{\circ} \mathrm{C}$. It consists of a paraffin core encapsulated by melamine formaldehyde shell as detailed in [25].

The forthcoming sub-sections describe numerical homogenization for effective property-prediction and application of effective properties towards thermal response evaluation of a macro-scale pavement section with a view to highlight the influence of PCMs in concrete.

\subsection{Multiscale Numerical Homogenization for Prediction of Effective Thermal Properties:}

Here, a microstructure guided numerical simulation framework is employed at multiple length scales to compute the effective properties of both the concretes. At every length scale, a representative volume element (RVE) is generated with the inclusion phases. Intrinsic thermal and mechanical properties are then assigned to the component phases in the RVE. Periodic boundary conditions [26,27] are applied. The RVE is meshed and FE analyses are carried out. A post processing module generates volume averaged responses that are computed to yield effective properties. The basic framework for the procedure is illustrated in Figure 1.
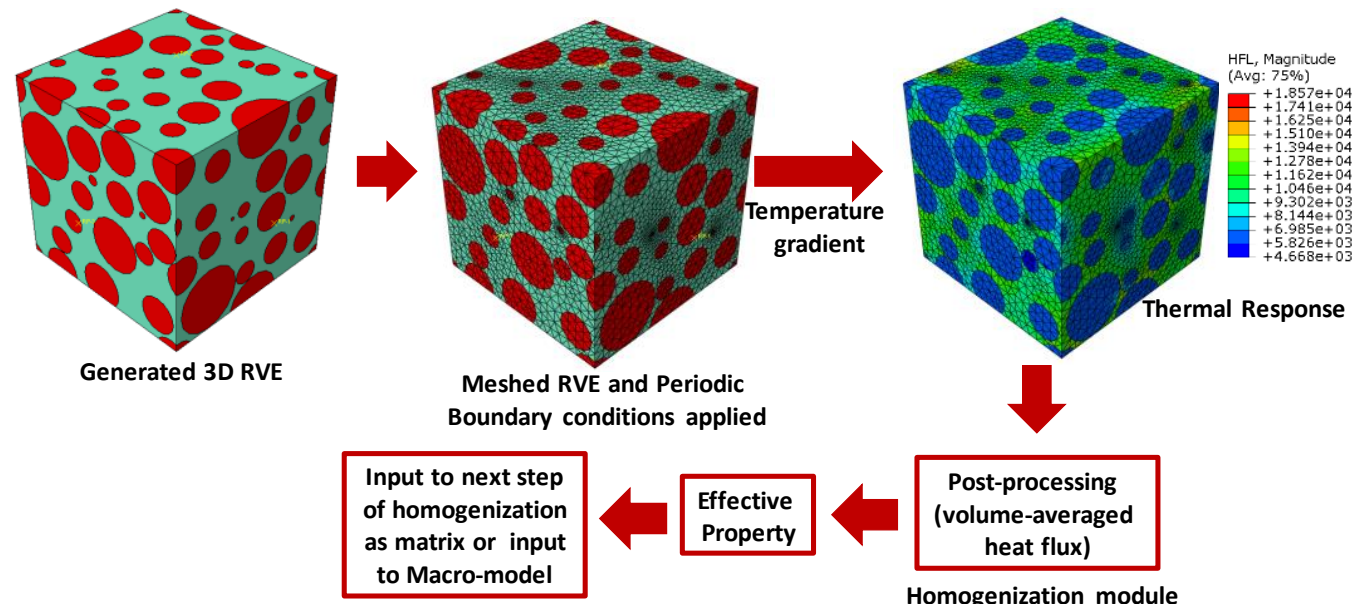

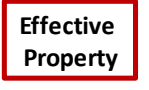

Property

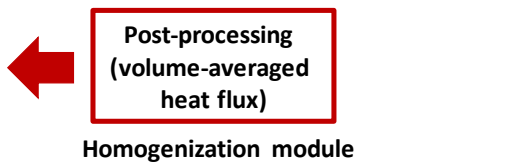


Figure 1: A schematic representation of the framework to obtain the effective properties from the intrinsic properties of constituent phases

The following sub-sections present the multiscale numerical homogenization procedure to obtain the effective properties of both the concretes.

\subsubsection{Generation of Microstructure and Boundary Conditions:}

3D representative volume elements (RVEs) are generated using the Lubachhevsky-Stillinger algorithm [28-31]. A hard particle contact model is employed, while ensuring there is no particle overlap. The formulations regarding the generation of the RVEs are adequately described in [26,27,32]. The meshed microstructure is implemented in a Python script and the analysis is performed in ABAQUS ${ }^{\mathrm{TM}}$ solver.

Periodic boundary conditions (PBC) [33-36] are applied on the RVE. Periodicity provides higher computational efficiency in smaller analysis domain and thus facilitates faster convergence [27]. Periodic boundary conditions (PBC) ensure continuity of temperature and heat flux at the boarder of neighboring unit cells. PBCs have been applied successfully towards prediction of effective properties of heterogeneous composites [26] and are detailed adequately in [33-36]. Figure 2 presents the microstructures generated for multi-scale homogenization.

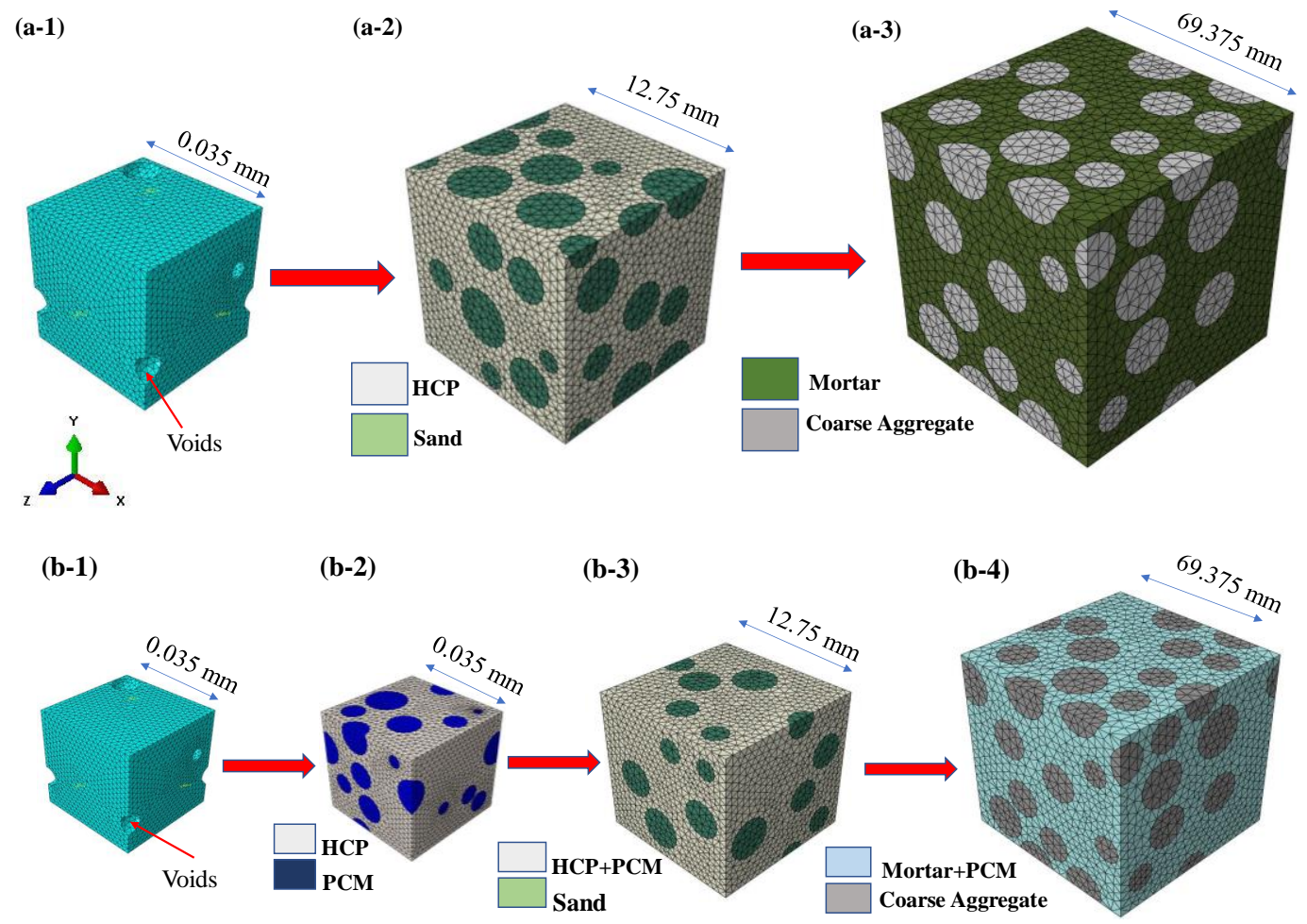

Figure 2: The meshed 3D RVEs for (a)control concrete: (a-1) Step I: air voids in HCP; (a-2) Step II: sand in homogenized matrix from step-I; (a-3) Step III: coarse aggregate in homogenized matrix from step-II 
and (b) PCM incorporated concrete: (b-1) Step I: air voids in HCP; (b-2) PCM in homogenized matrix from step-I ;(b-3) sand in homogenized matrix from step- II ; (b-4) coarse aggregate in homogenized matrix from step-III

A three step homogenization procedure is followed for the case of control concrete. The first step homogenizes air voids with hardened cement paste (Figure 2 (a-1)) whereas the second step homogenizes sand into the homogenized matrix obtained from first step (Figure 2 (a-2)). The final step incorporates coarse aggregates into the homogenized matrix obtained from second step (Figure 2 (a-3)) and thus, effective property of concrete is computed.

While a three-step homogenization is employed for control concrete, an additional step involving homogenization of PCMs is adopted for PCM-modified concrete. The first step of homogenization remains the same as control concrete case. In the second step, microencapsulated PCMs are incorporated into the homogenized matrix obtained from the first step as shown in Figure 2 (b-2). The third and fourth steps homogenizes sand (Figure 2 (b-3)) and coarse aggregate (Figure 2 (b-4)), respectively, into the homogenized matrix obtained from the previous step. These homogenizations are performed here at multiple steps in order to reduce the computational cost while maintaining computational efficiency [37]. The relative edge lengths of RVEs with respect to inclusion sizes are computed (Shown in Figure 2) based on sensitivity study. Similar relative sizes of RVEs with respect to inclusion sizes were obtained elsewhere [26,27]. The size distribution of inclusions (air voids, PCMs, sand and coarse aggregates) are adopted from $[22,25,26]$. The absolute volume fractions of component phases are shown in Table 1 . The volume fractions of the individual components of control concrete are denoted as $\mathrm{V}_{\mathrm{f}}^{\mathrm{a}}$ whereas those for PCM-modified concrete are denoted as $V_{f}^{b}$. The thermal analyses of the cases involving PCM are carried out at a temperature below the transition temperature implying that the microencapsulated PCMs are in the solid state.

Table 1. A table showing the volume fractions of the components of control concrete $\left(V_{f}^{a}\right)$ and PCMincorporated concrete $\left(V_{f}^{b}\right)$

\begin{tabular}{|c|c|c|}
\hline Component & $\mathrm{V}_{\mathrm{f}}^{\mathrm{a}}$ (Control Concrete) & $\mathrm{V}_{\mathrm{f}}^{\mathrm{b}}$ (PCM-Concrete) \\
\hline HCP & $24 \%$ & $24 \%$ \\
\hline Void & $6 \%$ & $6 \%$ \\
\hline PCM & NA & $6 \%$ \\
\hline Sand & $30 \%$ & $24 \%$ \\
\hline CA & $40 \%$ & $40 \%$ \\
\hline
\end{tabular}




\subsubsection{Effective Property Computation}

Once the RVE is generated using the Python script, it is meshed and subjected to FE analysis under externally applied unit temperature gradient along the X-direction. The FE analyses are carried out in ABAQUS ${ }^{\mathrm{TM}}$ solver. A MATLABC script operates on the result files containing the volume of the elements and the responses to obtain the effective properties as explained before. The intrinsic thermal properties of the constituent phases of both the concretes are shown in the Table 2.

Table 2. Thermal conductivity $(\lambda)$ [26], specific heat capacity $(C)[5]$ and latent heat $L[4,13]$ at $5.1^{\circ} \mathrm{C}$ for hardened cement paste (HCP), Sand, coarse aggregate (CA) and PCM

\begin{tabular}{|c|c|c|c|}
\hline Phases & $\lambda(\mathrm{W} / \mathrm{m} \mathrm{K})$ & $\mathrm{C}(\mathrm{J} / \mathrm{kg} \mathrm{K})$ & $\mathrm{L}(\mathrm{kJ} / \mathrm{kg})$ \\
\hline HCP & 0.75 & 750 & NA \\
\hline Sand & 2.8 & 1150 & NA \\
\hline PCM & 0.15 & 2600 & 150 \\
\hline CA & 2.3 & 790 & NA \\
\hline
\end{tabular}

A thermal analysis is carried out on the RVE containing C3D8R elements under a unit thermal gradient across opposite faces of the RVE along the X-direction. The thermal analysis results for different homogenization steps are shown in Figure 3 (a-1), (a-2) and (a-3) for the control concrete and in Figure 3 (b-1), (b-2), (b-3) and (b-4) for the PCM incorporated concrete). 


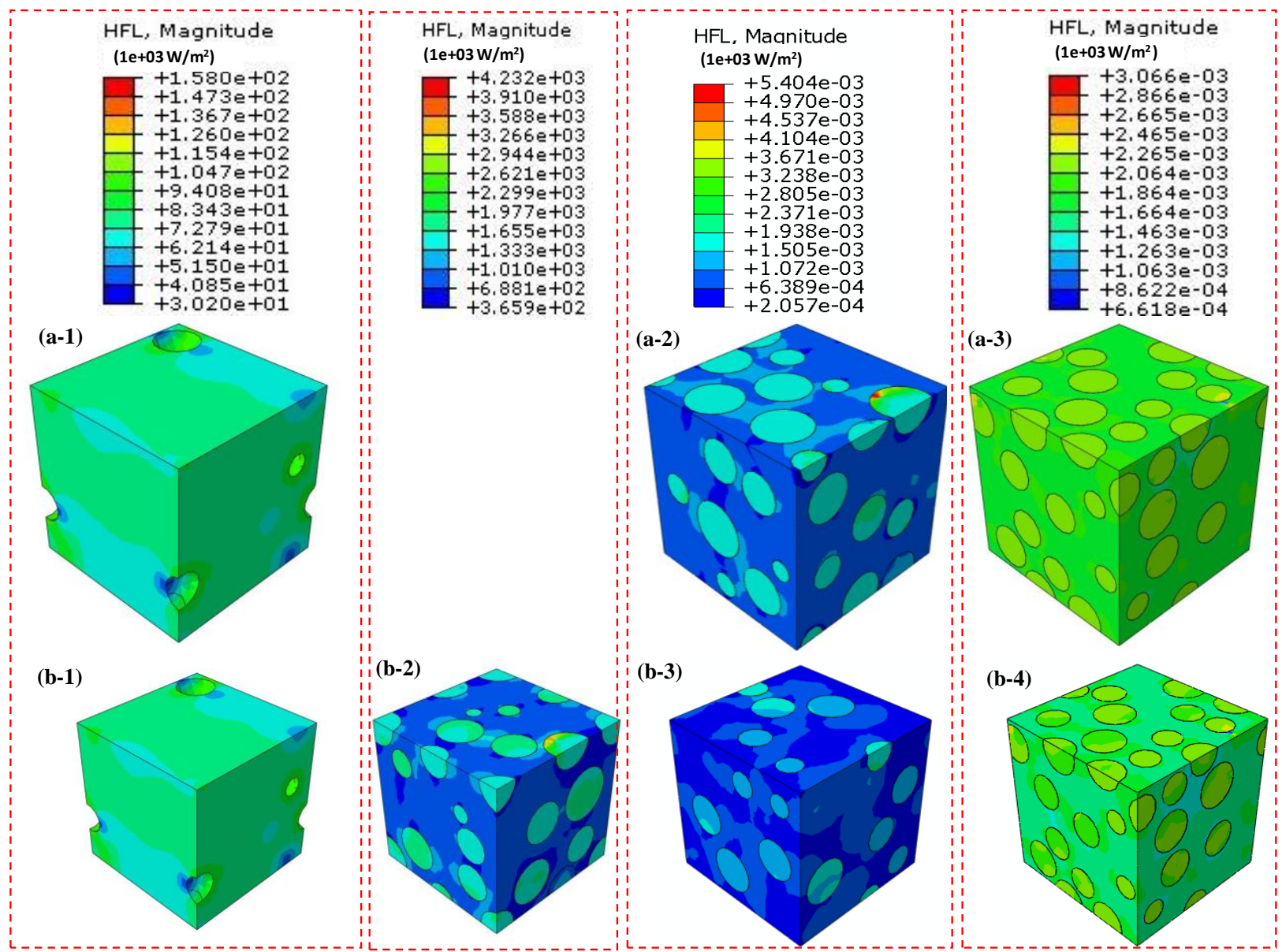

Figure 3: Heat flux for (a) control concrete corresponding to different homogenization steps (RVEs shown in Figure 2): (a-1) Step I: air voids in HCP: Homogenized thermal conductivity $(\lambda): 0.73 \mathrm{~W} / \mathrm{m} \mathrm{K}$; (a-2) Step-II: sand in homogenized matrix from step-I: Homogenized $\lambda$ : $0.56 \mathrm{~W} / \mathrm{m} \mathrm{K}$; (a-3) Step-III: : coarse aggregate in homogenized matrix from step-II: Homogenized $\lambda: 1.76 \mathrm{~W} / \mathrm{m} \mathrm{K}$ and for PCM-incorporated concrete corresponding to: (b-1) step I: air voids in HCP: Homogenized $\lambda$ : $0.6 \mathrm{~W} / \mathrm{m} \mathrm{K}$; (b-2) Step II: PCM in homogenized matrix from step-I: Homogenized $\lambda$ : $0.53 \mathrm{~W} / \mathrm{m} \mathrm{K}$; (b-3) Step-III: sand in homogenized matrix from step- II: Homogenized $\lambda: 1.43 \mathrm{~W} / \mathrm{m} \mathrm{K}$; (b-4) Step-IV: coarse aggregate in homogenized matrix from step-III: Homogenized $\lambda: 1.78 \mathrm{~W} / \mathrm{m} \mathrm{K}$. All the heat flux values correspond to externally applied unit temperature gradient $\left(1^{\circ} \mathrm{C} / \mathrm{mm}\right)$ in $\mathrm{X}$-direction.

A post processing module (MATLAB $\odot$ subroutine) computes the volume average of the heat flux. The volume-averaged heat flux is used to obtain the effective thermal conductivity using Equation 1 [26].

$$
\lambda_{e f f}=\bar{q}^{e}\left(L / T_{x=L}-T_{x=0}\right)
$$

where $\lambda_{e f f}$ is the effective thermal conductivity, $\bar{q}^{e}$ is the homogenized (volume averaged of all elements) heat flux in RVE, $L$ is the edge length of RVE. The temperatures on the two opposite faces of the unit cell along the X-direction are denoted by $T_{x=0}$ and $T_{x=L}$. Thus, $\left(T_{x=L}-T_{x=0}\right)$ is the imposed temperature 
difference. The aforementioned 3D numerical homogenization technique for effective thermal conductivities has been successfully validated in a previous study [26] against experimental thermal conductivities obtained using a guarded hot plate apparatus in accordance with ASTM C177-13 [38]. The effective thermal conductivities of a multi-inclusion porous systems is often predicted on the basis of a microstructure guided study [26,39] which have shown substantial agreement with experimental results. In order to obtain the effective volumetric heat capacity, the reaction heat flux is obtained at the nodes under applied unit temperature gradient along X-direction. The ratio of the volume-averaged reaction heat flux to the temperature difference yields the effective volumetric heat capacity $\left(\rho C_{p}\right)_{e f f, s}$ [40]. For the case of PCM incorporated concrete, a similar procedure is followed to obtain $\left(\rho C_{p}\right)_{e f f, s}$ that has PCM in the solid state. However, at the transition temperature of the PCMs, the latent heat released by the PCM during phase transformation is appended to the volumetric heat capacity as shown in Equation 2 [5].

$$
\left(\rho C_{p}\right)_{e f f, t}=\left(\rho C_{p}\right)_{e f f, s}+\left(\left(\phi_{c} \rho_{c} h_{s f}\right) / \Delta T_{p c}\right)
$$

where $\left(\rho C_{p}\right)_{e f f, t}$ is the effective volumetric heat capacity at transition temperature, $\left(\rho C_{p}\right)_{e f f, s}$ is the effective volumetric heat capacity for solid phase PCM, $\phi_{c}$ is volume fraction of PCM, $\rho_{c}$ is density of $\mathrm{PCM}, h_{s f}$ is latent heat of fusion of PCMs and $\Delta T_{p c}$ is the phase change temperature window. It is to be noted that all the calculations involved herein consider PCMs in solid state only, for the sake of simplicity. Similar approach has been successfully implemented in $[5,13]$.

The effective properties obtained using the above-mentioned framework for both control and PCMmodified concretes are presented in Table 3. The values obtained for control concrete are in line with experimental values reported in literature [5,13]. For the cases of PCM inclusions, the values match closely with the ones reported in [5,26]. The effective thermal properties, thus obtained, are used in macro-scale simulation of pavement in the forthcoming section to elucidate the influence of microstructural modifications imparted by PCMs on the macro-scale structures.

Table 3. The effective properties obtained after homogenization

\begin{tabular}{|l|c|c|}
\hline Materials & $\lambda(\mathrm{W} / \mathrm{m} \mathrm{K})$ & $\left(\rho C_{p}\right)_{e f f, s}(\mathrm{~J} / \mathrm{kg} \mathrm{K})$ \\
\hline Concrete & 1.4 & 880 \\
\hline PCM incorporated concrete & 1.78 & 928 \\
\hline
\end{tabular}

\subsection{Simulation of Thermal Response of Macro-scale Concrete Pavements:}

In this section macro-scale FE analysis is performed to elucidate the influence of PCMs on the thermal performance of concrete pavement. Consequently, the temperature profiles of the pavement are obtained under the local weather conditions in Providence, Rhode Island, United States. Forthcoming sub-sections 
present the model geometry, boundary conditions, analysis procedure and the thermal responses obtained from the numerical simulation as follows:

\subsubsection{Model Geometry and Boundary Conditions:}

A three-dimensional pavement section is modeled in FE commercial software ABAQUS ${ }^{\mathrm{TM}}$ as shown in Figure 4. The pavement section, considered here, is $13.3 \mathrm{~m}$ long and $9.15 \mathrm{~m}$ wide. The thickness of the top layer, made of concrete, is $406 \mathrm{~mm}$ which is lying over a subgrade of $12.20 \mathrm{~m}$ thickness. Such a configuration ensures that the subgrade is semi-infinite since the boundary effects are mitigated on the top pavement section when such a depth is considered [41].

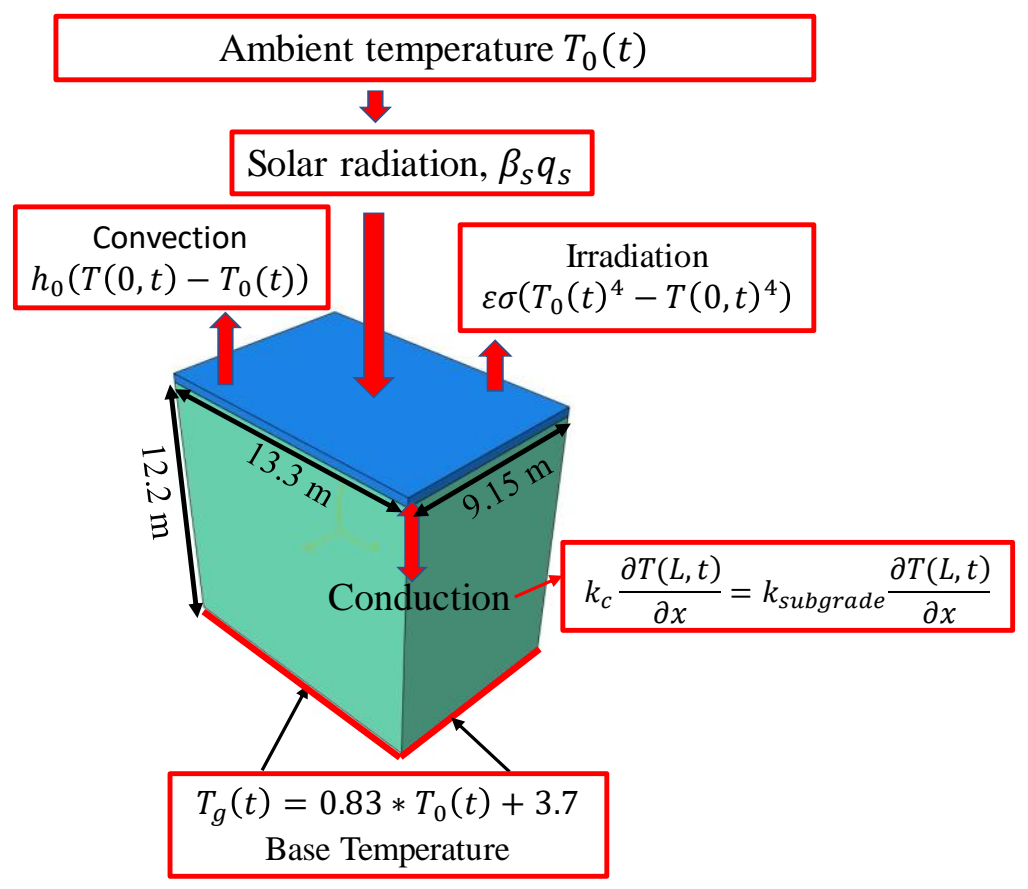

Figure 4: 3D geometry of pavement section showing the ambient interactions and thermal boundary conditions

The boundary conditions of the macro-scale pavement model are determined by the ambient conditions. The daily weather data for Providence, Rhode Island, United States are obtained from the National Oceanic and Atmospheric Administration (NOAA) [42]. It includes hourly global horizontal irradiance (GHI) data and hourly atmospheric temperature data. GHI encompasses the short wave radiations diffused in the atmosphere and the solar radiation incident on a surface normal to the rays thus resulting in the total amount of short wave radiation received per unit area of a horizontal surface on the ground. The ambient interactions and the temperature boundary conditions are shown in Figure 4 . The daily maximum GHI $\left(q_{s}\right)$ values are adjusted for absorption by concrete with its absorptivity $\left(\beta_{s}\right)$ being 0.59 [43] and are applied as surface heat flux thermal load valid only during the day in the model. The hourly ambient temperature $\left(T_{0}\right)$ is used to 
define the heat transfer interactions. Convection is defined by the product of surface convection coefficient $\left(h_{0}\right)$ and the difference of the pavement surface temperature $(T(0, t))$ and ambient temperature $\left(T_{0}\right)$ [44]. The value of $h_{0}$ is a function of wind velocity which can be assumed to be $26 \mathrm{~W} / \mathrm{m}^{2} \mathrm{~K}$ for the air-concrete interface at low wind speeds [45] and is applied as a surface film coefficient in the model that defines the convective interaction between the pavement surface and the atmosphere. The Stefan-Boltzmann radiation constant $(\sigma)$ and the surface emissivity of concrete $(\varepsilon)$ with values $5.6697 \times 10^{-8} \mathrm{~W} / \mathrm{m}^{2} \mathrm{~K}^{4}$ and 0.92 respectively, when multiplied with the difference of the fourth powers of ambient temperature $\left(T_{0}\right)$ and pavement surface temperature $T(0, t)\left(\varepsilon \sigma\left(T_{0}^{4}-T(0, t)^{4}\right)\right)$ give the radiative heat transfer. This is modelled by defining a surface radiation interaction between the pavement surface and the atmosphere with an ambient temperature of $T_{0}$. The temperature at the base of the pavement (here below the subgrade) $\left(T_{g}\right)$ is a function of the ambient temperature $T_{0}$ and the relationship is shown as follows [46]:

$$
T_{g}(t)=0.83 * T_{0}(t)+3.7
$$

Temperature boundary conditions are applied to the base of the pavement model. Another boundary condition stems from the heat flux continuity equation at the interface between the top concrete layer and bottom subgrade layer. This interaction is defined in the model with a surface-to-surface contact, thereby ensuring a conductive heat flow at the interface. While the conductivity of concrete is obtained from numerical homogenization (Table 3), conductivity of subgrade is adopted as $1.75 \mathrm{~W} /(\mathrm{m} . \mathrm{K})$ [47]. For the case of PCM incorporated concrete, the significant jump in internal energy during phase change is accounted for by defining the latent heat as a thermal property of the material. A nonlinear transient heat analysis step in the model ensures that the latent heat in conjunction with the density of the material successfully attenuates the heat capacity in the phase change temperature window as mentioned earlier. Thus, as the pavement in the model cools down in absence of solar radiation and plunging ambient temperature, the PCMs having a volume fraction of $6 \%\left(V_{f}\right)$, release $150 \mathrm{~kJ} / \mathrm{kg}\left(h_{s f}\right)$ at $5.1^{\circ} \mathrm{C}\left(T_{p c}\right)$. Density of $300 \mathrm{~kg} / \mathrm{m}^{3}$ for PCMs is adopted here [25]. This study incorporates a phase transformation temperature window $\left(\Delta T_{p c}\right)$ of $1^{\circ} \mathrm{C}$ which is in line with values reported elsewhere [5]. At the transition temperature of the PCMs, the latent heat released by the PCM during phase transformation is added to the volumetric heat capacity (Equation 2), obtained using numerical homogenization as explained before.

\subsubsection{Finite Element Simulation of Macro-scale Response:}

A MATLAB $($ ) script extracts the data from the weather data files and feeds it into the ABAQUSTM model. The conductive, radiative and convective heat transfer processes are considered in the python script for ABAQUS $^{\text {TM }}$ solver. A transient heat transfer FE analysis is carried out in ABAQUS ${ }^{\text {TM }}$ solver. A mesh convergence study was performed. The top concrete layer containing 280 linear hexahedral DC3D8 
elements and the bottom subgrade layer containing 630 linear hexahedral DC3D8 elements ensured converged solution. A post processing module extracts the temperature data of the pavement for both concrete and PCM-modified concrete cases which are reported in Figure 5 for the months of December 2015, January 2016 and February 2016.
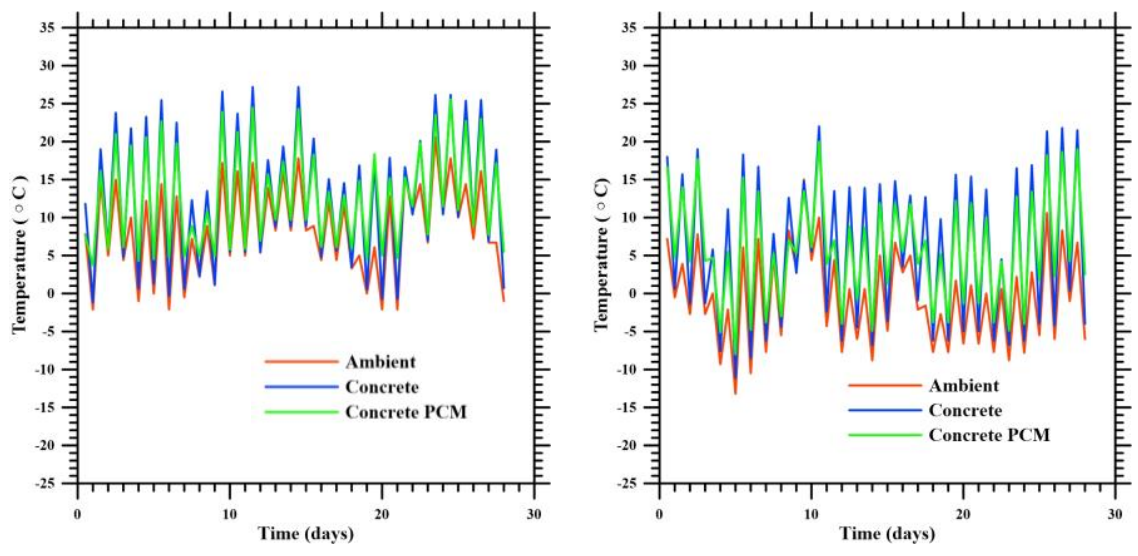

(a)

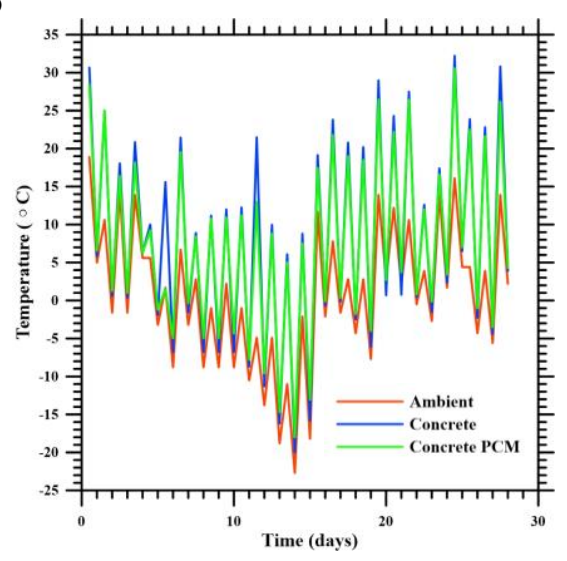

(c)

Figure 5: Surface temperature profile of both the concretes contrasted with the ambient temperature for the first four weeks of (a) December 2015, (b) January 2016 and (c) February 2016

The ambient temperature is also depicted in Figure 5 for reference. As can be seen from the figure, the pavement surface temperature for both concrete systems is higher than the peak ambient temperature which can be attributed to the solar radiation that heats up the surface. Similar observations were noted elsewhere $[10,13]$. Figure 5 also clearly shows that temperature peak of control concrete is higher than the temperature peak of the PCM-incorporated concrete when the temperature is greater than the phase transition temperature of $5.1{ }^{\circ} \mathrm{C}$. The reduced temperature peak obtained in the PCM incorporated concrete substantiates the effective solar energy storage capacity of PCMs which would otherwise be wasted in raising the surface temperature as obtained in the control concrete. The effectiveness of the PCM incorporated concrete lies in its ability to store the energy during its phase change as a latent heat in the 
charging cycle (under incoming solar radiation) that can be released at lower temperatures in the discharging cycle towards effective defrosting. From Figures 5(a), (b) and (c), it is clear that the amplitude of temperature variations (difference between maximum and minimum pavement temperature) reduces significantly when PCM is incorporated. The difference is more pronounced for lower ambient temperatures. This is attributed to the release of latent heat during phase-transformation (liquid to solid) of PCMs at transition temperature of $5.1^{\circ} \mathrm{C}$. Thus, the temperature profiles shown here reflect the effectiveness of these PCMs in keeping the pavement surface warmer even under very low ambient temperatures, thereby establishing the fact that such PCMs are extremely effective in the New England area of the United States facilitating enhanced service life. Similar observations were found experimentally in [13]. In order to shed more light, Figure 6 shows the pavement temperature profiles for January 7, 2016. Figure 6 (a-1) and (b-1) correspond to maximum ambient temperature of $7.2^{\circ} \mathrm{C}$ and peak solar radiation of $384 \mathrm{~W} / \mathrm{m}^{2}$ for control concrete and PCM-incorporated concrete respectively.

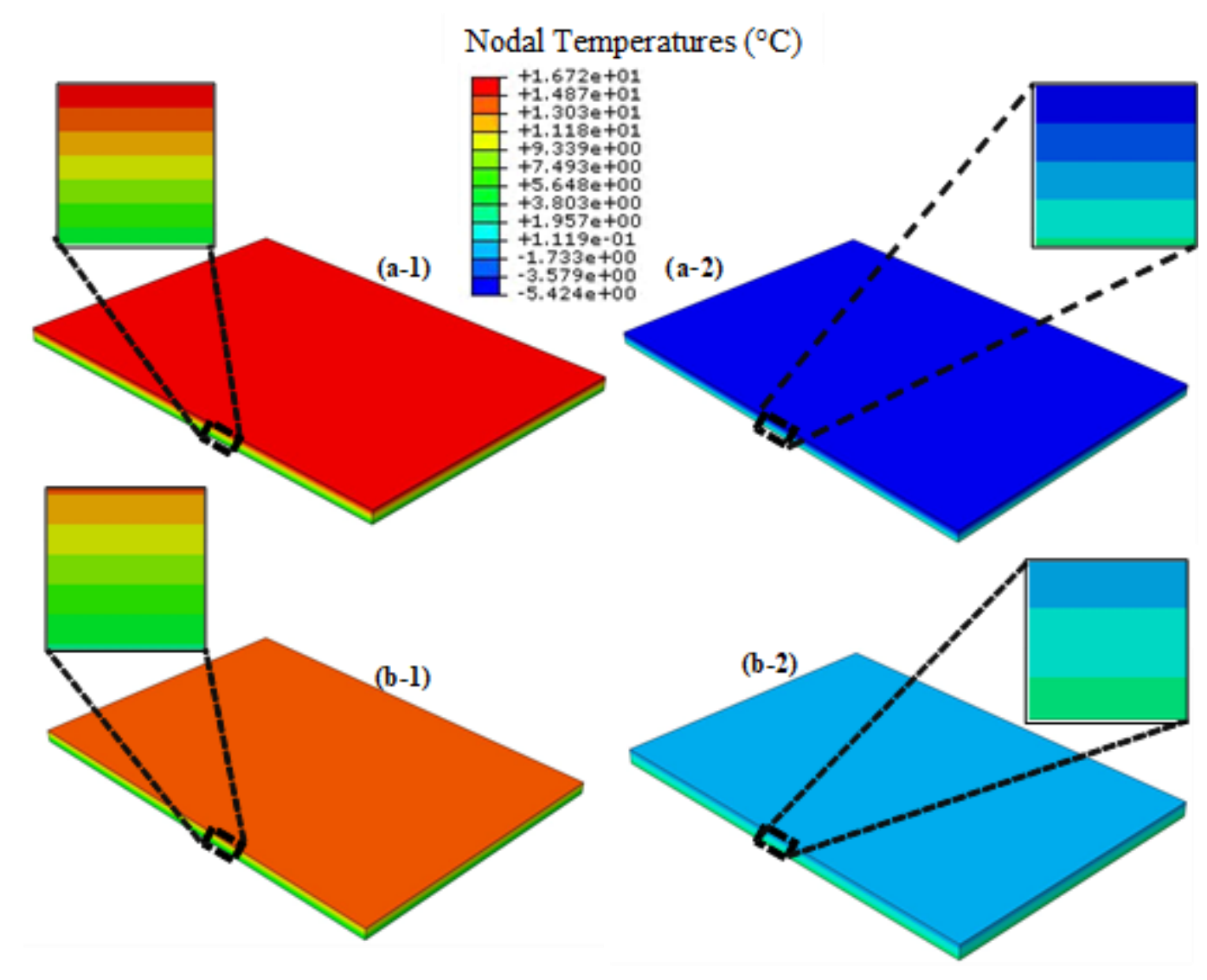

Figure 6: Pavement temperature profiles on January 7, 2016 for: (a-1) control concrete pavement corresponding to maximum temperature $\left(7.2^{\circ} \mathrm{C}\right)$ of the day; $(\mathrm{a}-2)$ control concrete pavement corresponding to minimum ambient temperature $\left(-7.1^{\circ} \mathrm{C}\right)$; (b-1) PCM-incorporated concrete pavement corresponding to maximum temperature $\left(7.2^{\circ} \mathrm{C}\right)$; (b-2) PCM-incorporated concrete pavement corresponding to minimum ambient temperature $\left(-7.1^{\circ} \mathrm{C}\right)$ 
PCM-incorporated concrete shows slightly lower temperatures under the same ambient temperature as expected. Figures 6 (a-2) and (b-2) show the pavement temperatures corresponding to minimum ambient temperature of the day for control concrete and PCM-incorporated concrete respectively. While the control concrete pavement shows significantly lower pavement temperatures (minimum temperature $-5.4{ }^{\circ} \mathrm{C}$ ), the $\mathrm{PCM}$-incorporated concrete shows relatively higher pavement temperatures (minimum temperature $-1.3^{\circ} \mathrm{C}$ ).

This is attributed to the heat released by PCMs during phase-transformation thus helping to keep the pavement warmer. Considering a water-freezing temperature of $-6.1^{\circ} \mathrm{C}$ in concrete $[13,48]$, the control concrete pavement is expected to freeze at this minimum ambient temperature of on January 7, 2016 whereas the PCM-incorporated concrete does not freeze. Overall, considering a freezing and thawing temperature of $-6.1^{\circ} \mathrm{C}$ and $0^{\circ} \mathrm{C}$ respectively in concrete $[13,48]$, the control concrete experiences 25 freezethaw cycles, whereas the PCM-incorporated concrete experiences 13 number of freeze-thaw cycles during December 2015 - February 2016 (Surface temperatures reported in Figure 5) thereby reinforcing the idea that PCMs have the potential to enhance the service life of pavements. In order to shed more light into the effectiveness of the PCMs, simulation of frost-damage in both the concretes is elucidated in the forthcoming section.

\section{INFLUENCE OF PCM ON THE FREEZE THAW RESPONSE OF CONCRETE AND MORTAR MICROSTRUCTURE}

While the previous section employed microstructure-guided numerical simulation at different length scales to obtain the macro-scale thermal response of concrete pavement, this section applies the pavement surface temperatures, obtained in the previous section for February 2016, to the meso scale so as to elucidate the fundamental difference in freeze-thaw response imparted by PCMs in concretes. The forthcoming subsections show microstructure-guided numerical simulation for frost-damage response in concretes and mortars using continuum damage mechanics. The analysis involves generation of meshed 2D representative element areas (REAs) by Python scripts. The physical change in the phase transformation of water to ice during the freezing cycle leads to a volume increase of $9 \%$ in the micro-pores [49]. The damage in the cementitious matrix of the REA is implemented in ABAQUS ${ }^{\mathrm{TM}}$ with the help of a user defined subroutine UMAT that implements the damage laws. A post processing module computes the degraded Young's modulus from the results obtained by ABAQUS ${ }^{\mathrm{TM}}$ solver. The analysis procedure and the results are presented as follows:

\subsection{Microstructures and Material Properties:}

The damage analysis is carried out at the mortar scale. Here, 2D REAs are chosen to reduce computational demand as a trade-off between computational efficiency and demand [50]. The REAs are generated using 
Lubachevsky-Stillinger algorithm [26,28-31]. The edge lengths of REAs are chosen as five times the mean diameter of inclusions based on a sensitivity study. Similar RVE sizes relative to inclusion sizes are implemented successfully in [27,32]. Figure 7(a) shows the control mortar microstructure containing $40 \%$ hardened cement paste with $10 \%$ voids and $50 \%$ sand by volume. The REA for PCM-incorporated mortar is shown in Figure 7(b) which contains 20\% PCM as sand-replacement. The PCM-modified mortar microstructure contains $40 \%$ hardened cement paste with $10 \%$ voids, $40 \%$ sand and $10 \%$ PCM (20\% sand replacement) by volume. The size distribution of PCM and sand are adopted from [25].

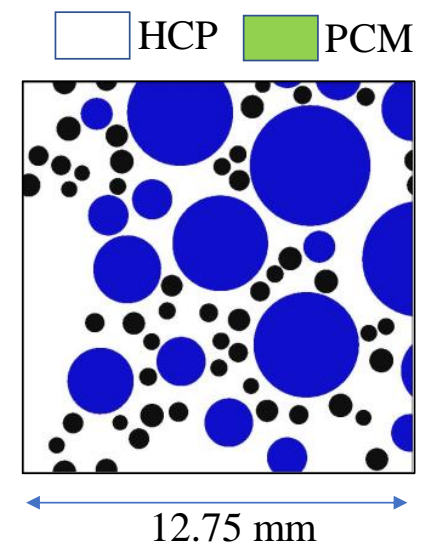

(a)

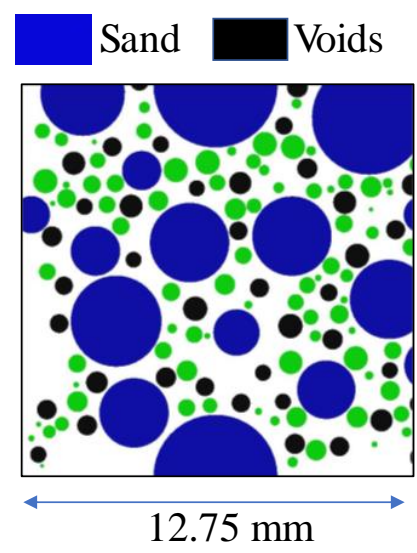

(b)

Figure 7: The generated REAs for: (a) mortar matrix containing 50\% sand and 40\% hardened cement paste (HCP) with 10\% void; (b) PCM-modified mortar containing 40\% HCP, $10 \%$ void, $40 \%$ sand and $10 \%$ PCM by volume.

The analysis requires the material properties for the matrix and inclusion phases which are shown in Table 4. The poison's ratio for all components except PCMs is taken as 0.2 . A poison's ratio of 0.4 is adopted for PCMs [25].

Table 4. Input material properties for numerical simulation of damage [22,25,37]

\begin{tabular}{|c|c|c|}
\hline Component & $\mathrm{E}(\mathrm{GPa})$ & $\alpha\left(\mu \varepsilon /{ }^{\circ} \mathrm{C}\right)$ \\
\hline HCP & 22.4 & 15 \\
\hline Sand & 70 & 5 \\
\hline PCM & 4.45 & 25 \\
\hline
\end{tabular}

\subsection{Numerical Simulation of Isotropic Damage in Concretes:}

The damage analysis is implemented in python language program which is later used in ABAQUS ${ }^{\mathrm{TM}}$ solver to obtain results. A user-defined subroutine in ABAQUS ${ }^{\mathrm{TM}}$ applies the volume expansion (due to freezing) in the voids embedded in the cement paste matrix. The resulting mechanical response is captured by the 
framework that applies the damage law. The mechanical properties are used from Table 4 while the size distribution is similar to what has been implemented earlier in the study. Finally, a post processing module computes the stress-strain response after every freeze-thaw cycle and yields the degraded material properties of the mortar which is scaled up to the concrete level and validated with experimental results reported in [49].

Periodic boundary conditions [33-36] are implemented in the REAs as described earlier. The framework assumes fully saturated voids. The analysis framework imports the surface temperatures of the pavement from the macro scale analysis (for the month of February 2016 as shown in Figure 5(c)) and applies volumetric expansion in the voids as soon as the freezing temperature of $-6.1^{\circ} \mathrm{C}[13,51]$ is reached. The volumetric expansion is implemented using a user-defined subroutine in ABAQUS ${ }^{\mathrm{TM}}$ that incorporates volumetric thermal expansion of voids by means of artificial coefficient of thermal expansion of the void so as to obtain $9 \%$ volumetric expansion. The volume expansion is released when the average nodal temperature increases above $0^{\circ} \mathrm{C}$ (Thawing temperature $\left.[13,52]\right)$. Such freeze-thaw cycle induce damage around the voids which propagates with increasing number of freeze-thaw cycles.

The progressive damage in HCP matrix due to freeze-thaw cycles is implemented by user defined subroutine UMAT [53-55] in ABAQUS ${ }^{\mathrm{TM}}$. The progressive degradation of both the mortars due to frostdamage is modelled here by continuum damage mechanics while considering the heterogeneity in these materials [21-23]. Assuming isotropic stiffness degradation, the damage variable, $D$ is given as [21-24,56]:

$$
\sigma=(1-D) C: \varepsilon
$$

Where the effective stress tensor is denoted by $\sigma, C$ denotes fourth order tensor of elasticity and $\varepsilon$ is the strain tensor. The value of damage, $\mathrm{D}$ ranges from 0 (undamaged) to 1 (completely damaged). The damage rate denoted by $\dot{D}$ assumes only zero or positive values which can be explained by its proportionality with the damage energy release rate [22].

In order to characterize the damage in the cement paste matrix at the scale of the mortar (Figures 7(a) and (b)), an isotropic damage model is used that provides a damage evolution law as shown in Equation 5 [57].

$$
\dot{D}=\xi\left(\partial S\left(\epsilon^{e q}\right) / \partial \epsilon^{e q}\right)
$$

Where $\xi$ is the Lagrange multiplier which when multiplied with the partial derivative of the constraint $S\left(\epsilon^{e q}\right)$ (as mentioned in Equation 6) with respect to the $\epsilon^{e q}$ (elastic energy) gives the rate of scalar damage $\dot{D}$. The constraint $S\left(\epsilon^{e q}\right)$ is defined as follows:

$$
S\left(\epsilon^{e q}\right)=1-\exp \left[-\left(\left(\epsilon^{e q}-a\right) / b\right)^{c}\right]-D
$$


$S\left(\epsilon^{e q}\right)$ is constrained to be $\leq 0$. The damage evolution law (Equation 5) is discretized by an implicit Euler scheme and it yields the instantaneous damage parameter $D$. The fitting parameters $\mathrm{a}, \mathrm{b}$ and $\mathrm{c}$ (in Equation 6) for cement paste, adopted from [57], are 0.488, 0.1 and 3.0 respectively. For the PCM incorporated mortar, same damage parameter values are implemented since the matrix is HCP for both the cases.

\subsection{Frost-damage Response:}

Figure 8 shows progressive damage in mortars for both the cases. The figure shows progressive frostdamage in both the mortars for the month of February in the year 2016 in Providence, Rhode Island, United States. The model geometries for control and PCM-incorporated mortar are shown again in Figure 8(a-1) and (b-1) for the ease of reference. While Figures 8 (a-2) and (a-3) exhibit progressive damage on February 10 and February 28 respectively for the control mortar, Figures 8 (b-2) and (b-3) show the damage status on February 10 and February 28 respectively for the PCM-incorporated mortar. While the control concrete has experienced 10 freeze thaw cycles, the PCM incorporated concrete has experienced 5 such events over the month of February, 2016. As the damage progresses, on day 10, for the control mortar, the HCP matrix (Figure 8(a-2)) shows significant damage whereas the damage is negligible for the PCM incorporated HCP matrix in the PCM modified mortar (Figure $8(\mathrm{~b}-2)$ ). This is attributed to the fact that PCMs act as heat storage and releases heat when the ambient temperature starts to drop decreasing the amplitude of diurnal temperature fluctuations in the pavement. As a result, the number of freeze-thaw cycle experienced by pavement reduces due to incorporation of PCM in the mortar which is reflected here in the form of significant reduction in damage when PCM is incorporated. This trend is continued till the end of the month (Day 28) as shown in Figure 8 (a-3) and (b-3). 


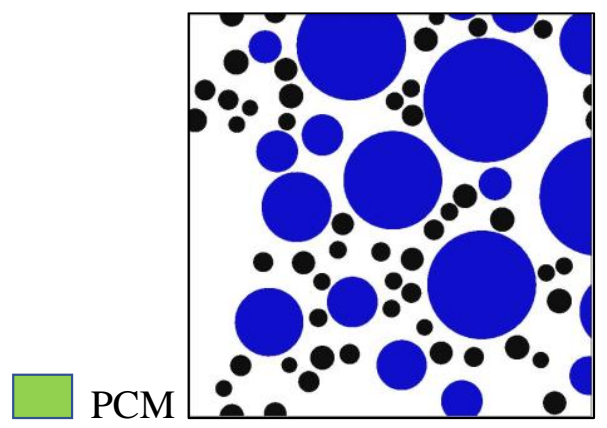

Sand

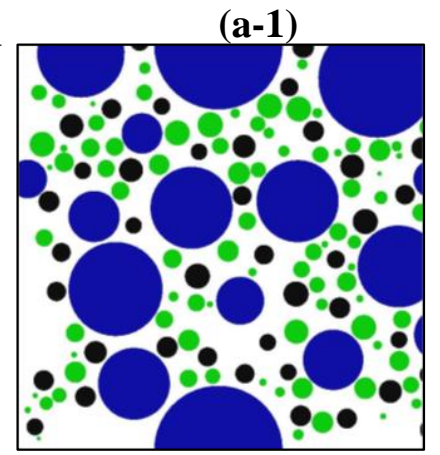

(b-1)

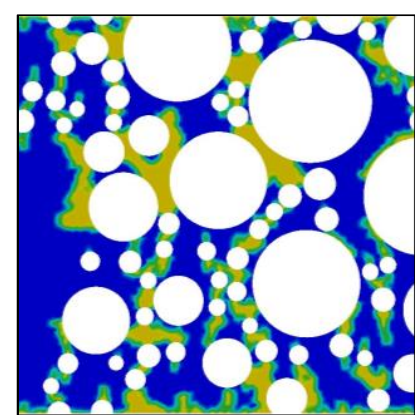

(a-2)

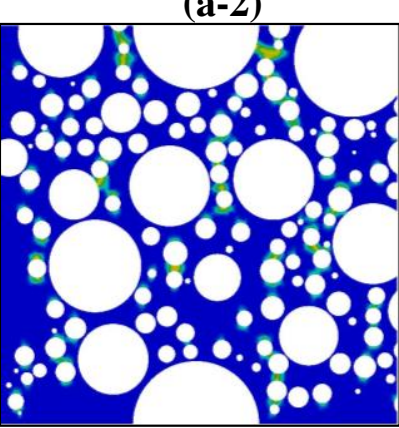

(b-2)

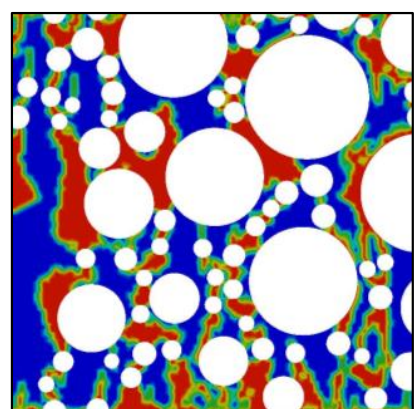

(a-3)

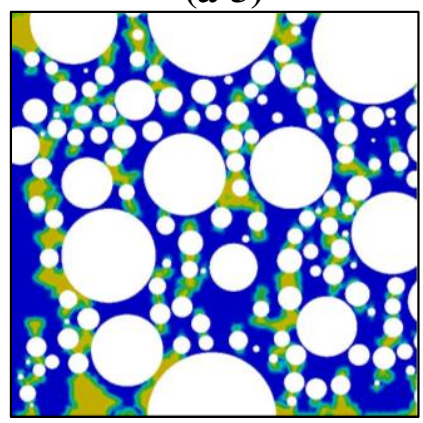

(b-3)
Damage

0.95

0.83125

0.7125

0.59375

0.475

0.35625

0.2375

0.11875

0

Figure 8: Progressive damage in mortars: (a-1) model geometry for control mortar, (a-2) damage in control mortar on Day 10; (a-3) damage in control mortar on Day 28; (b-1) model geometry for PCMincorporated mortar, (b-2) damage in PCM-incorporated mortar on Day 10; (a-3) damage in PCMincorporated mortar on Day 28

Degraded Young's modulus $\left(E_{\mathrm{d}}\right)$ values for both the mortars corresponding to days in the month of February 2016 are calculated from the damage values using equation 4 and are reported in Figure 9(a). The PCMincorporated mortar experiences significant reduction in frost-degradation as comparted to control mortar which is primarily attributed to the lower number of freeze-thaw cycles experienced by PCM-incorporated mortar due to thermal heat storage capacity of PCMs as explained earlier. Degraded Yung's modulus values obtained for mortar are numerically homogenized with coarse aggregates ( $40 \%$ by volume) to obtain degraded Young's modulus for concretes as shown in Figure 9(b). PCM incorporated concrete show a lesser degree of degradation than control concrete as expected. While the control concrete shows a $25.5 \%$ degradation, the PCM incorporated concrete shows a $15 \%$ for the same time period which fundamentally reinforces the efficacy of using PCMs towards improving freeze-thaw durability of cementitious materials. 

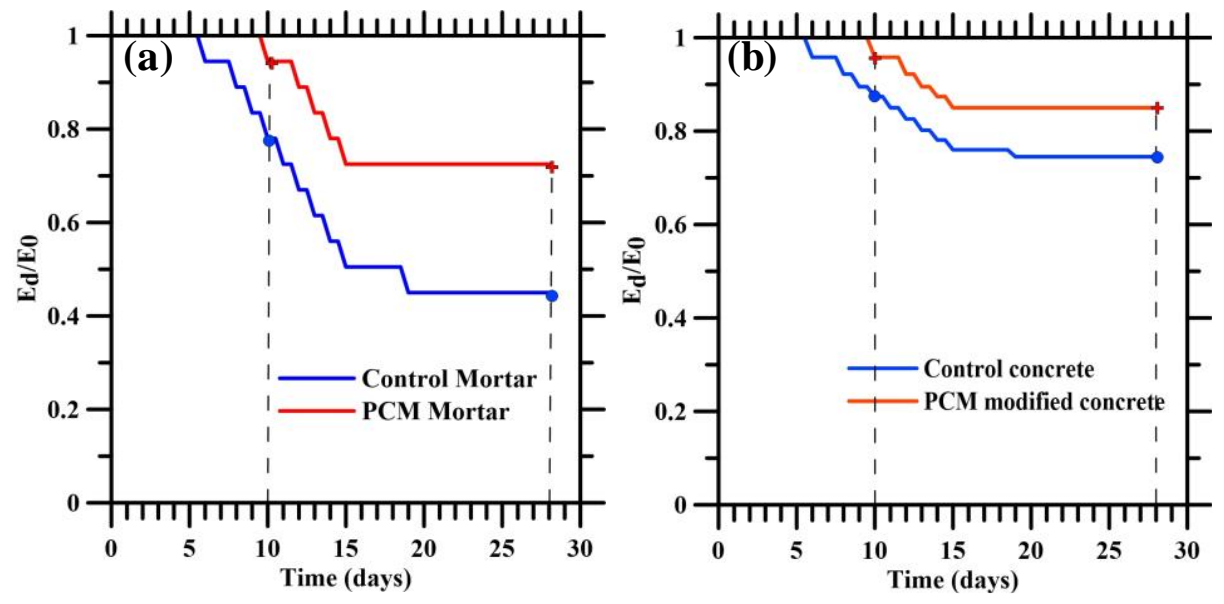

Figure 9: Ratios of degraded Young's modulus $\left(E_{d}\right)$ to initial Young's modulus $\left(E_{0}\right)$ with number of days of February for (a) mortars and (b) concrete for control and PCM-incorporated concretes respectively highlighting Days 10 and 28 (see Figure 8)

In order to shed more light on the predictive capability of the numerical simulation framework, the frostdamage results from numerical analysis for control concrete are compared to experimental results reported in [49]. Here the ratios of degraded Young's modulus $\left(E_{d}\right)$ to initial Young's modulus $\left(E_{0}\right)$ are plotted for up to 10 number of freeze-thaw cycles. The predicted values correlate very well with the experimental values signifying robustness of the numerical simulation framework in predicting freeze-thaw response in cementitious materials. The numerical simulation framework thus integrates the material microstructure to the macro-scale structural performance and provides an efficient means to optimize these concretes for durable infrastructure.

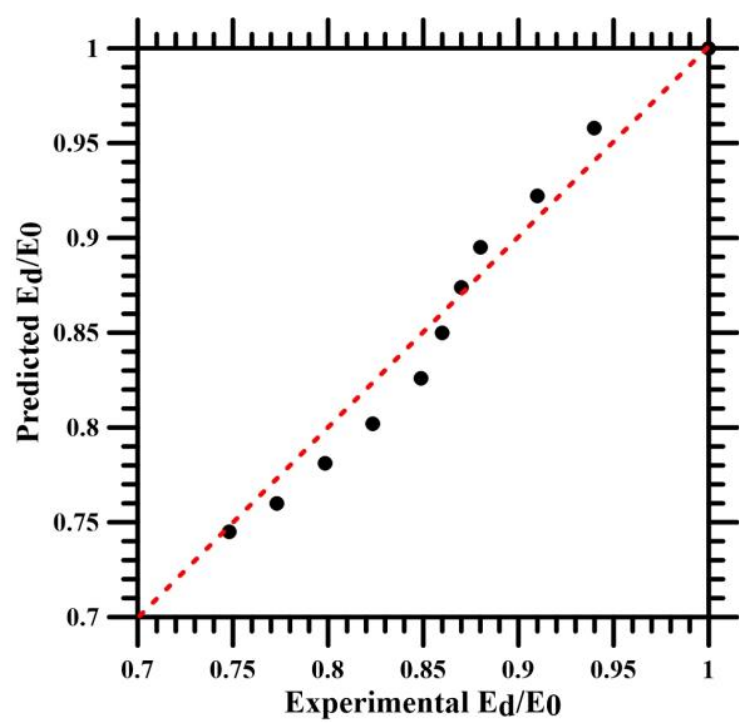

Figure 10: Predicted vs experimental ratios of degraded Young's modulus $\left(\mathrm{E}_{\mathrm{d}}\right)$ to initial Young's modulus $\left(\mathrm{E}_{0}\right)$ for concrete 


\section{CONCLUSIONS}

This paper presents microstructure-guided numerical simulations at different length scales to evaluate the influence of PCMs on the freeze-thaw response of concrete pavements. Two different concretes were employed for evaluations. While the control concrete contains $70 \%$ aggregate by volume, the PCMmodified concrete contains 20\% PCM as sand-replacement (6\% absolute volume). A three-step numerical homogenization was performed for control concrete and an additional step involving PCMs was incorporated in PCM-modified concrete. The effective properties, thus obtained from the numerical homogenization, were employed in macro-scale concrete pavement model to obtain the pavement temperatures under the influence of ambient temperatures and solar radiation. The analysis was performed for ambient conditions at Providence, Rhode Island, United States during December 2015-February 2016. The PCM incorporated concrete pavements showed a significantly reduced amplitude of pavement temperature fluctuations as compared to that obtained for control concrete. This is attributed to the latent heat storage capability of the PCM which is released at its transition temperature. The results also indicate $50 \%$ reduction in the number of freeze-thaw cycles, experienced by pavement, when PCMs are incorporated. In order to shed more light into the influence of PCMs on the frost damage response of concretes, an isotropic damage model was employed to capture the progressive frost deterioration of the mortar and concrete. A superior frost damage-resistance of the PCM modified concrete was observed as compared to control concrete signifying effectiveness of the PCMs. For the month of February 2016, the control concrete experienced $25.5 \%$ loss of stiffness whereas the PCM-modified concrete showed about $15 \%$ loss of stiffness. This advocates the use of PCMs in concrete pavements with a view to enhance frostdamage resistance of concrete pavements. The microstructure guided numerical simulation framework, presented in this paper, provides an efficient means of designing concretes by tweaking the material at different length scales to maximize performance.

\section{ACKNOWLEDGEMENTS}

The authors gratefully acknowledge the support from College of Engineering (COE) and Department of Civil and Environmental Engineering at the University of Rhode Island (URI) towards this study.

\section{REFERENCES}

[1] D.P. Bentz, R. Turpin, Potential applications of phase change materials in concrete technology, Cement and Concrete Composites. 29 (2007) 527-532.

[2] P. Bamonte, A. Caverzan, N. Kalaba, M. Lamperti Tornaghi, Lightweight Concrete Containing Phase Change Materials (PCMs): A Numerical Investigation on the Thermal Behaviour of Cladding Panels, Buildings. 7 (2017) 35.

[3] T.-C. Ling, C.-S. Poon, Use of phase change materials for thermal energy storage in concrete: An overview, Construction and Building Materials. 46 (2013) 55-62. 
[4] Y. Farnam, H.S. Esmaeeli, P.D. Zavattieri, J. Haddock, J. Weiss, Incorporating phase change materials in concrete pavement to melt snow and ice, Cement and Concrete Composites. 84 (2017) 134-145.

[5] A.M. Thiele, G. Sant, L. Pilon, Diurnal thermal analysis of microencapsulated PCM-concrete composite walls, Energy Conversion and Management. 93 (2015) 215-227.

[6] A.M. Thiele, A. Jamet, G. Sant, L. Pilon, Annual energy analysis of concrete containing phase change materials for building envelopes, Energy Conversion and Management. 103 (2015) 374-386.

[7] L.F. Cabeza, C. Castellón, M. Nogués, M. Medrano, R. Leppers, O. Zubillaga, Use of microencapsulated PCM in concrete walls for energy savings, Energy and Buildings. 39 (2007) 113-119. doi:10.1016/j.enbuild.2006.03.030.

[8] Y. Konuklu, M. Ostry, H.O. Paksoy, P. Charvat, Review on using microencapsulated phase change materials (PCM) in building applications, Energy and Buildings. 106 (2015) 134155 .

[9] T. Khadiran, M.Z. Hussein, Z. Zainal, R. Rusli, Advanced energy storage materials for building applications and their thermal performance characterization: A review, Renewable and Sustainable Energy Reviews. 57 (2016) 916-928.

[10] A. Arora, G. Sant, N. Neithalath, Numerical simulations to quantify the influence of phase change materials (PCMs) on the early- and later-age thermal response of concrete pavements, Cement and Concrete Composites. 81 (2017) 11-24.

[11] B. Šavija, E. Schlangen, Use of phase change materials (PCMs) to mitigate early age thermal cracking in concrete: Theoretical considerations, Construction and Building Materials. 126 (2016) 332-344.

[12] F. Fernandes, S. Manari, M. Aguayo, K. Santos, T. Oey, Z. Wei, G. Falzone, N. Neithalath, G. Sant, On the feasibility of using phase change materials (PCMs) to mitigate thermal cracking in cementitious materials, Cement and Concrete Composites. 51 (2014) 14-26.

[13] H.S. Esmaeeli, Y. Farnam, D.P. Bentz, P.D. Zavattieri, W.J. Weiss, Numerical simulation of the freeze-thaw behavior of mortar containing deicing salt solution, Mater Struct. 50 (2017) 96.

[14] G.G. Litvan, Frost action in cement in the presence of De-Icers, Cement and Concrete Research. 6 (1976) 351-356.

[15] T.C. Powers, A Working Hypothesis for Further Studies of Frost Resistance of Concrete, JP. 41 (1945) 245-272.

[16] Li Wenting, Pour-Ghaz Mohammad, Castro Javier, Weiss Jason, Water Absorption and Critical Degree of Saturation Relating to Freeze-Thaw Damage in Concrete Pavement Joints, Journal of Materials in Civil Engineering. 24 (2012) 299-307.

[17] Y. Farnam, S. Dick, A. Wiese, J. Davis, D. Bentz, J. Weiss, The influence of calcium chloride deicing salt on phase changes and damage development in cementitious materials, Cement and Concrete Composites. 64 (2015) 1-15.

[18] Y. Farnam, A. Wiese, D. Bentz, J. Davis, J. Weiss, Damage development in cementitious materials exposed to magnesium chloride deicing salt, Construction and Building Materials. 93 (2015) 384-392.

[19] Y. Farnam, D. Bentz, A. Sakulich, D. Flynn, J. Weiss, Measuring Freeze and Thaw Damage in Mortars Containing Deicing Salt Using a Low-Temperature Longitudinal Guarded Comparative Calorimeter and Acoustic Emission, ACEM. 3 (2014) 316-337. doi:10.1520/ACEM20130095. 
[20] H.S. Esmaeeli, Y. Farnam, J.E. Haddock, P.D. Zavattieri, W.J. Weiss, Numerical analysis of the freeze-thaw performance of cementitious composites that contain phase change material (PCM), Materials \& Design. 145 (2018) 74-87.

[21] M. Koniorczyk, D. Gawin, B.A. Schrefler, Modeling evolution of frost damage in fully saturated porous materials exposed to variable hygro-thermal conditions, Computer Methods in Applied Mechanics and Engineering. 297 (2015) 38-61.

[22] P. Wriggers, S.O. Moftah, Mesoscale models for concrete: Homogenisation and damage behaviour, Finite Elements in Analysis and Design. 42 (2006) 623-636.

[23] J. Mazars, A description of micro- and macroscale damage of concrete structures, Engineering Fracture Mechanics. 25 (1986) 729-737.

[24] J. Mazars, G. Pijaudier-Cabot, From damage to fracture mechanics and conversely: A combined approach, International Journal of Solids and Structures. 33 (1996) 3327-3342.

[25] M. Aguayo, S. Das, A. Maroli, N. Kabay, J.C.E. Mertens, S.D. Rajan, G. Sant, N. Chawla, $\mathrm{N}$. Neithalath, The influence of microencapsulated phase change material (PCM) characteristics on the microstructure and strength of cementitious composites: Experiments and finite element simulations, Cement and Concrete Composites. 73 (2016) 29-41.

[26] S. Das, M. Aguayo, S.D. Rajan, G. Sant, N. Neithalath, Microstructure-guided numerical simulations to predict the thermal performance of a hierarchical cement-based composite material, Cement and Concrete Composites. 87 (2018) 20-28.

[27] S. Das, A. Maroli, S.S. Singh, T. Stannard, X. Xiao, N. Chawla, N. Neithalath, A microstructure-guided constitutive modeling approach for random heterogeneous materials: Application to structural binders, Computational Materials Science. 119 (2016) 52-64.

[28] H.A. Meier, E. Kuhl, P. Steinmann, A note on the generation of periodic granular microstructures based on grain size distributions, International Journal for Numerical and Analytical Methods in Geomechanics. 32 (2008) 509-522.

[29] B.D. Lubachevsky, F.H. Stillinger, E.N. Pinson, Disks vs. spheres: Contrasting properties of random packings, Journal of Statistical Physics. 64 (1991) 501-524.

[30] B.D. Lubachevsky, F.H. Stillinger, Geometric properties of random disk packings, Journal of Statistical Physics. 60 (1990) 561-583.

[31] B.D. Lubachevsky, How to simulate billiards and similar systems, Journal of Computational Physics. 94 (1991) 255-283.

[32] S. Das, P. Yang, S.S. Singh, J.C.E. Mertens, X. Xiao, N. Chawla, N. Neithalath, Effective properties of a fly ash geopolymer: Synergistic application of X-ray synchrotron tomography, nanoindentation, and homogenization models, Cement and Concrete Research. 78 (2015) 252-262.

[33] S. Das, A. Maroli, N. Neithalath, Micromechanical Modeling for Material Design of Durable Infrastructural Materials: The Influence of Aggregate and Matrix Modification on Elastic Behavior of Mortars, International Conference on Durability of Concrete Structures. (2016).

[34] K. Mohsen, A.G. Straatman, A thermal periodic boundary condition for heating and cooling processes, International Journal of Heat and Fluid Flow. 28 (2007) 329-339.

[35] J. Sanahuja, C. Toulemonde, Numerical homogenization of concrete microstructures without explicit meshes, Cement and Concrete Research. 41 (2011) 1320-1329.

[36] O. van der Sluis, P.J.G. Schreurs, W.A.M. Brekelmans, H.E.H. Meijer, Overall behaviour of heterogeneous elastoviscoplastic materials: effect of microstructural modelling, Mechanics of Materials. 32 (2000) 449-462. 
[37] G. Constantinides, F.-J. Ulm, The effect of two types of C-S-H on the elasticity of cementbased materials: Results from nanoindentation and micromechanical modeling, Cement and Concrete Research. 34 (2004) 67-80.

[38] M. Aguayo, S. Das, C. Castro, N. Kabay, G. Sant, N. Neithalath, Porous Inclusions as Hosts for Phase Change Materials in Cementitious Composites: Characterization, Thermal Performance, and Analytical Models, Construction and Building Materials. Under Review (2016).

[39] L. Qiu, H. Zou, D. Tang, D. Wen, Y. Feng, X. Zhang, Inhomogeneity in pore size appreciably lowering thermal conductivity for porous thermal insulators, Applied Thermal Engineering. 130 (2018) 1004-1011.

[40] S. Minapoor, S. Ajeli, M.J. Toghchi, Simulation of Non-Crimp 3D Orthogonal Carbon Fabric Composite for Aerospace Applications Using Finite Element Method, 9 (2015) 9.

[41] J.M. Duncan, C.L. Monismith, E.L. Wilson, Finite element analysis of pavements, Highway Research Record. 228 (1968) 18-33.

[42] National Oceanic and Atmospheric Administration, (2018). http://www.noaa.gov/ (accessed May 25, 2018).

[43] K. Riding, J. Poole, A. Schindler, Temperature Boundary Condition Models for Concrete Bridge Members, ACI Materials Journal. (2007) 379-387.

[44] ASTM Standard, C680-10, Standard practice for estimate of the heat gain or loss and the surface temperatures of insulated flat, cylindrical and spherical systems by use of computer programs.

[45] Saetta Anna, Scotta Roberto, Vitaliani Renato, Stress Analysis of Concrete Structures Subjected to Variable Thermal Loads, Journal of Structural Engineering. 121 (1995) 446457. doi:10.1061/(ASCE)0733-9445(1995)121:3(446).

[46] I. Yoshitake, S. Nagai, T. Tanimoto, S. Hamada, Simple estimation of the ground water temperature and snow melting process, in: Proceedings of the 11th International Road Weather Conference, 2002.

[47] S. Lu, T. Ren, Y. Gong, R. Horton, An Improved Model for Predicting Soil Thermal Conductivity from Water Content at Room Temperature, Soil Science Society of America Journal. 71 (2007) 8-14.

[48] B. Zuber, J. Marchand, Modeling the deterioration of hydrated cement systems exposed to frost action: Part 1: Description of the mathematical model, Cement and Concrete Research. 30 (2000) 1929-1939.

[49] F. Gong, Y. Wang, D. Zhang, T. Ueda, Mesoscale Simulation of Deformation for Mortar and Concrete under Cyclic Freezing and Thawing Stress, ACT. 13 (2015) 291-304. doi:10.3151/jact.13.291.

[50] W. Zhou, C. Zhao, X. Liu, X. Chang, C. Feng, Mesoscopic simulation of thermo-mechanical behaviors in concrete under frost action, Construction and Building Materials. 157 (2017) 117-131.

[51] Z. Sun, G.W. Scherer, Effect of air voids on salt scaling and internal freezing, Cement and Concrete Research. 40 (2010) 260-270. doi:10.1016/j.cemconres.2009.09.027.

[52] M. Koniorczyk, D. Gawin, B.A. Schrefler, Modeling evolution of frost damage in fully saturated porous materials exposed to variable hygro-thermal conditions, Computer Methods in Applied Mechanics and Engineering. 297 (2015) 38-61. doi:10.1016/j.cma.2015.08.015. 
[53] A. Benallal, R. Billardon, I. Doghri, An integration algorithm and the corresponding consistent tangent operator for fully coupled elastoplastic and damage equations, Communications in Applied Numerical Methods. 4 (1988) 731-740.

[54] J. Lemaitre, R. Desmorat, M. Sauzay, Anisotropic damage law of evolution, European Journal of Mechanics - A/Solids. 19 (2000) 187-208.

[55] F. ABAQUS, ABAQUS 6.14 Documentation, Dassault Systemes, Providence, RI, USA. (2014).

[56] J. Mazars, G. Pijaudier-Cabot, Continuum Damage Theory-Application to concrete, Journal of Engineering Mechanics. 115 (1989).

[57] M. Hain, P. Wriggers, Numerical homogenization of hardened cement paste, Comput Mech. 42 (2008) 197-212. 